\title{
Brachylaima spp. (Trematoda) parasitizing Cornu aspersum (Gastropoda) in France with potential risk of human consumption
}

\author{
Claudia Gérard ${ }^{1, *}$, Armelle Ansart ${ }^{1}$, Nolwenn Decanter ${ }^{1}$, Marie-Claire Martin ${ }^{1}$, and Maxime Dahirel ${ }^{1,2}$ \\ ${ }^{1}$ Université de Rennes, CNRS, ECOBIO (Ecosystèmes, biodiversité, Évolution) - UMR 6553, 35000 Rennes, France \\ ${ }^{2}$ INRAE, Université Côte d'Azur, CNRS, ISA (Institut Sophia Agrobiotech), 06903 Sophia-Antipolis, France
}

Received 20 December 2019, Accepted 4 March 2020, Published online 13 March 2020

\begin{abstract}
The edible land snail Cornu aspersum, native to the Mediterranean coastlines of North Africa, is widely distributed on most continents and often invasive in areas where introduction is recent. This species could contribute to the geographic spread of parasites as demonstrated for Brachylaima spp. These cosmopolitan trematodes may represent a threat to human health, like in Australia where Brachylaima cribbi infects humans. In this study, we demonstrate for the first time the occurrence of Brachylaima spp. in two French populations of $C$. aspersum, Thorigné-Fouillard (Illeet-Vilaine), and Arçais (Deux-Sèvres), with an overall prevalence of 10.4\% (Thorigné-Fouillard) and 73.3\% (Arçais), respectively and a metacercarial intensity on average three times higher in Thorigné-Fouillard (37) than in Arçais (11). Cornu aspersum may act as a first and second intermediate host, as demonstrated in Arçais. The morphometrics of metacercariae, particularly the great body length about $2 \mathrm{~mm}$, discriminate our Brachylaima species from those already described in C. aspersum (B. cribbi in Australia, and B. aspersae, B. llobregatensis and B. mascomai in Europe). Molecular analysis, based on $28 \mathrm{~S}$ and COI, suggests the occurrence of two species in our study, one of which is probably Brachylaima mesostoma, an intestinal parasite of passeriform birds described in Central Europe. We underline the need for further research to identify species of Brachylaima in France and measure the health hazard of consuming field-collected snails.
\end{abstract}

Key words: Cornu aspersum, Brachylaima, Prevalence, Edible land snail, Trematode, Human parasitosis.

Résumé - Brachylaima spp. (Trematoda) parasitant Cornu aspersum (Gastropoda) en France et risque potentiel pour la consommation humaine. L'escargot Cornu aspersum, originaire des côtes méditerranéennes d'Afrique du Nord, est largement répandu sur la plupart des continents et souvent invasif dans ses aires d'introduction récente. Cette espèce peut contribuer à l'expansion géographique de parasites comme démontré pour Brachylaima spp. Ces trématodes cosmopolites peuvent représenter une menace pour la santé comme en Australie où Brachylaima cribbi parasite l'espèce humaine. Dans cette étude, nous démontrons pour la première fois la présence de Brachylaima spp. dans deux populations françaises de C. aspersum, à Thorigné-Fouillard (Ille-et-Vilaine) et Arçais (Deux-Sèvres), avec une prévalence totale de $10.4 \%$ (Thorigné-Fouillard) et $73.3 \%$ (Arçais), et une intensité de métacercaires en moyenne trois fois plus importante à Thorigné-Fouillard (37) qu'à Arçais (11). Cornu aspersum peut jouer le rôle de premier et de second hôte intermédiaire, comme démontré à Arçais. La morphométrie des métacercaires, en particulier la grande taille corporelle d'environ $2 \mathrm{~mm}$ de long, suggèrent qu'il ne s'agit pas d'espèces de Brachylaima déjà décrites chez $C$. aspersum (B. cribbi en Australie et B. aspersae, B. llobregatensis et $B$. mascomai en Europe). L'analyse moléculaire, basée sur $28 \mathrm{~S}$ et COI, suggère la présence de deux espèces dans notre étude, dont l'une est probablement Brachylaima mesostoma, un parasite intestinal d'oiseaux passeriformes décrit en Europe Centrale. Nous soulignons le besoin de recherche future pour identifier les espèces de Brachylaima présentes en France et mesurer le risque associé à la consommation d'escargots terrestres prélevés en milieu naturel.

\section{Introduction}

The land snail Cornu aspersum aspersum Müller (syn. Helix aspersa) (Gastropoda), native to the Mediterranean

\footnotetext{
*Corresponding author: claudia.gerard@univ-rennesl.fr
}

coastlines of North Africa, is now widely distributed, occurring on all continents except Antarctica, as well as on numerous islands [1, 20, 21]. Cornu aspersum is particularly abundant in human-disturbed habitats under favorable climatic conditions (Mediterranean temperate and subtropical) and is considered an invasive and pest species in many regions of its introduced 
areas, such as in the Americas and Oceania [1, 20]. Its successful spread is at least partly explained by inadvertent and intentional human introductions, but also by high phenotypic plasticity resulting in various adaptive morpho-anatomic, physiological, and behavioral responses to environmental fluctuations (e.g., [14, 29, 39, 41]).

When invasive species serve as hosts, they can strongly influence infectious disease dynamics in invaded areas (for reviews: [12, 46, 47]). It is therefore crucial to know the parasitofauna recorded in invasive host species in order to understand or predict the possible impacts of their parasites. Helminth parasites of $C$. aspersum are mostly Nematoda (at least 16 species including four facultative parasite species) (Table 1), and to a lesser extent Trematoda (Dicrocoelium dendriticum and four species of Brachylaima) (Table 2). Some authors [15] clearly demonstrated that imported edible C. aspersum specimens could contribute significantly to the geographic spread of Brachylaima species, in their case between Spain and Africa. Cornu aspersum also plays a key role in the transmission of emerging helminthiases of veterinary importance such as feline aelurostrongylosis and canine angiostrongylosis [9, 10]. Moreover, some species parasitizing C. aspersum at the larval stage such as Angiostrongylus cantonensis and Brachylaima cribbi can infect humans as definitive hosts with a lethal risk ( $>10 \%$ and $5-10 \%$ mortality rate without treatment, respectively), and thus, represent a serious human health hazard [13, 31, 55]. More generally, species of the genus Brachylaima may have both veterinary and medical significance since they can occur in various domestic birds and mammals, including poultry, pigeons, pigs, rabbits, and dogs, representing potential reservoirs for human infection [22, 34, 43, 57].

Up to now, B. cribbi is the first brachylaimid trematode known to infect humans and is recorded exclusively in Australia [31]. Human brachylaimiasis (intestinal fluke infection) occurs after consumption of undercooked land snails including $C$. aspersum parasitized by infective metacercariae [3], or also by viable metacercariae deposited on vegetables via the snail's slime trail and excreta and/or crushed snails [6]. Hematophagous adults of $B$. cribbi inhabit the intestine, and their eggs are recovered in human feces [43]. Brachylaima cribbi is thought to be of European origin: most of its intermediate hosts are helicid species introduced to Australia from Europe, and the introduced European birds Turdus merula (common blackbird) and Sturnus vulgaris (common starling) are its most commonly infected natural definitive hosts among mammals, birds, and reptiles [3, 4].

Three other species of the cosmopolitan genus Brachylaima parasitize C. aspersum in other countries apart from Australia, all involving rodents as definitive hosts (Table 2). Brachylaima aspersae and Brachylaima llobregatensis use C. aspersum as first and second intermediate hosts in Spain, and also in Algeria for B. llobregatensis [15, 53]. Brachylaima mascomai, for which $C$. aspersum is one of the second intermediate host species, occurs in Spain and in South Africa [15]. An undetermined species of Brachylaima was also recorded in C. aspersum from Turkey, acting as first intermediate host [26]. In Europe, no epidemiological data are available up to now, except in Spain where the prevalence of Brachylaima
Table 1. Nematode species parasitizing Cornu aspersum as intermediate or definitive hosts.

\begin{tabular}{lc}
\hline Parasite species & References \\
\hline Cornu aspersum as intermediate host & \\
Order Strongylida & {$[9]$} \\
Aelurostrongylus abstrusus (Railliet, 1898) & {$[7]$} \\
Angiostrongylus cantonensis Chen, 1935 & {$[19]$} \\
Angiostrongylus dujardini Drozdz \& Doby, 1970 & {$[10]$} \\
$\quad$ Angiostrongylus vasorum (Baillet, 1866) & {$[8]$} \\
Crenosoma vulpis (Dujardin, 1844) & {$[44]$} \\
Morerastrongylus andersoni (Petter, 1972) & {$[51]$} \\
Neostrongylus linearis (Marotel, 1913) & {$[19]$} \\
Oslerus rostratus Gerichter, 1945 & {$[19]$} \\
Protostrongylus rufescens (Leuckart, 1865) & {$[7]$} \\
Troglostrongylus brevior Gerichter, 1948 & \\
Order: Rhabditida (facultative parasites) & {$[35]$} \\
$\quad$ Alloionema appendiculata Schneider, 1859 & {$[49]$} \\
Caenorhabditis elegans Maupas, 1900 & {$[35]$} \\
Phasmarhabditis hermaphrodita Schneider, 1859 & {$[35]$} \\
Rhabditis gracilicaudata de Man, 1876 & \\
Cornu aspersum as definitive host & \\
Order: Ascaridida & {$[37]$} \\
Nemhelix bakeri Morand \& Petter, 1986 & \\
Order: Rhabditida & {$[36]$} \\
Angiostoma aspersae Morand, 1986 &
\end{tabular}

spp. metacercariae in $C$. aspersum from marketplaces varies from $0 \%$ to $93.6 \%$ depending on the season and region [17]. It is worth highlighting the increasing worldwide interest in Brachylaima spp. infecting other terrestrial snail species, according to recent studies (e.g., [59, 60]). In France, a country bordering Spain, people consume between 25,000 and 30,000 tons of edible land snails per year, among them 800 1000 tons of $C$. aspersum produced on farms [32]. Moreover, C. aspersum is an anthropophilous species, quite common in urban areas and private gardens [25]. Due to the potential risk of brachylaimiasis for humans and domestic animals related to the consumption of infected land snails and/or vegetables with viable metacercariae, the main objective of our preliminary study was to investigate the occurrence of Brachylaima spp. in two allopatric populations of $C$. aspersum in France. If present, we also aimed (i) to research whether $C$. aspersum can act as first and/or second intermediate host, and (ii) to provide some morphological and molecular data for further comparison with Brachylaima species already described.

\section{Materials and methods \\ Study sites, sampling, and measurements}

We sampled two wild populations of $C$. aspersum in northwestern France, distant from each other by about $220 \mathrm{~km}$ as the crow flies. In total, 326 snails were collected at the end of hibernation/beginning of physiological awakening: 49 specimens from Thorigné-Fouillard (Department Ille-et-Vilaine, Region Bretagne; $\left.48^{\circ} 15^{\prime} 51^{\prime \prime} \mathrm{N}, 1^{\circ} 57^{\prime} 74^{\prime \prime} \mathrm{W}\right)$ on 18 February 2018 , and 277 specimens from Arçais (Department Deux-Sèvres, Region Nouvelle-Aquitaine; 46 $17^{\prime} 47.9^{\prime \prime} \mathrm{N}, 0^{\circ} 41^{\prime} 32.6^{\prime \prime} \mathrm{W}$ ) on 1 April 2018. Both populations inhabit private gardens, 
Table 2. Digenean trematode species parasitizing Cornu aspersum as first (Hi1) and/or second (Hi2) intermediate host.

\begin{tabular}{|c|c|c|c|c|}
\hline Parasite species & Larval stages in $\mathrm{Hi}(\mathrm{MH})$ & Definitive host & Country & References \\
\hline \multicolumn{5}{|l|}{ Plagiorchiida } \\
\hline Dicrocoelium dendriticum (Rudolphi, 1819) & $\mathrm{SP} / \mathrm{C}$ in Hi1 (DG) & Sheep, goats & Turkey & {$[23,26]$} \\
\hline \multicolumn{5}{|l|}{ Diplostomida } \\
\hline Brachylaima sp. Dujardin, 1843 & $\mathrm{SP} / \mathrm{C}$ in $\mathrm{Hil}(\mathrm{DG})$ & & Turkey & [26] \\
\hline Brachylaima aspersae Segade et al., 2011 & $\begin{array}{l}\mathrm{SP} / \mathrm{C} \text { in } \mathrm{Hi} 1(\mathrm{DG}) ; \mathrm{MC} \text { in } \mathrm{Hi} 2 \\
(\mathrm{~K})\end{array}$ & Rodents & Spain & [53] \\
\hline Brachylaima cribbi Butcher \& Grove, 2001 & $\mathrm{MC}$ in $\mathrm{Hi} 2(\mathrm{~K})$ & $\begin{array}{l}\text { Mammals, birds*, } \\
\text { reptiles }\end{array}$ & Australia & {$[3,4]$} \\
\hline $\begin{array}{l}\text { Brachylaima llobregatensis González-Moreno \& } \\
\text { Gracenea, } 2006\end{array}$ & $\begin{array}{l}\mathrm{SP} / \mathrm{C} \text { in } \mathrm{Hi} 1(\mathrm{DG}) ; \mathrm{MC} \text { in } \mathrm{Hi} 2 \\
(\mathrm{~K})\end{array}$ & Rodents & Algeria, Spain & {$[15,16]$} \\
\hline $\begin{array}{l}\text { Brachylaima mascomai Gracenea \& González-Moreno, } \\
2002\end{array}$ & $\mathrm{MC}$ in $\mathrm{Hi} 2(\mathrm{~K})$ & Rodents & $\begin{array}{l}\text { South Africa, } \\
\text { Spain }\end{array}$ & {$[15,18]$} \\
\hline
\end{tabular}

Larval stages: SP, sporocysts; C, cercariae; MC, metacercariae. MH, Microhabitat (MH) in parenthesis: DG, digestive gland; K, kidney.

* Introduced European Turdus merula and Sturnus vulgaris being the most commonly infected natural definitive hosts.

but in a suburban area for Thorigné-Fouillard, whereas rural for Arçais.

We distinguished adults from subadults by the presence of a reflected shell lip indicating the cessation of shell growth [1]. We froze all the snails prior to the search for larval trematodes in various organs (lungs, heart, kidney, body cavity, and digestive gland), and we dissected them using a binocular microscope. We observed trematodes (sporocysts, cercariae, and/or metacercariae), when present, under light glass coverslip pressure using bright-field and phase-contrast microscopy. We counted and morphologically identified sporocysts and metacercariae of Brachylaima spp. according to Gracenea and González-Moreno [18] and Segade et al. [53]. We performed measurements of metacercariae preserved in 95\% Ethanol, following Mas-Coma et al. [30]. Sporocysts and metacercariae of Brachylaima spp. were also preserved in $95 \%$ ethanol for DNA sequence analysis (see below).

We described parasitism by prevalence $(\mathrm{P} \%)$ (number of hosts infected with a particular parasite species/number of examined hosts), mean abundance (A) (average abundance of a parasite species among all members of a host sample), and mean intensity $(I)$ (total number of parasites of a particular species found in a sample/number of hosts infected with that parasite) [2].

\section{DNA sequencing of Brachylaima spp., alignment, and phylogenetic analyses}

We analyzed 13 sporocysts and 9 metacercariae of Brachylaima spp., each of them originating from a different snail, by molecular identification tools. DNA of each individual parasite (approximately $1 \mathrm{~mm}^{3}$ piece of sporocyst or whole body of a metacercaria) was extracted following [38]. Samples were lysed in $25 \mu \mathrm{L}$ of $0.02 \mathrm{~N} \mathrm{NaOH}$ at $99{ }^{\circ} \mathrm{C}$ for 30 min. We amplified fragments of ca. 1275 and $780 \mathrm{bp}$ (except one shorter sequence of $669 \mathrm{bp}$ ) for the nuclear 28S ribosomal DNA (rDNA) and mitochondrial COI DNA (mtDNA) genes, respectively. The 28S fragment was amplified using the forward primer dig12 $\left(5^{\prime}\right.$ - AAGCATATCACTAAGCGG - 3') and the reverse primer 1500R $\left(5^{\prime}\right.$ - GCTATCCTGAGGGAAACTTCG - 3') [58]. The COI region was amplified using the forward primer JB3 $\left(5^{\prime}-\right.$ TTTTTTGGGCATCCTGAGGTTTAT $\left.-3^{\prime}\right)$ and the reverse primer CO1-R trema $\left(5^{\prime}\right.$ - CAACAAATCATGATGCAAAAGG - 3') [33]. Amplification of template DNA was carried out in $12 \mu \mathrm{L}$ volumes with MyTaq Mix (2X) (Bioline, France), including $5 \mu \mathrm{M}$ of each primer and $2 \mu \mathrm{L}$ of DNA. The PCR conditions were $98{ }^{\circ} \mathrm{C}$ for $10 \mathrm{~s}$, $50{ }^{\circ} \mathrm{C}$ for $20 \mathrm{~s}$, and $68{ }^{\circ} \mathrm{C}$ for $90 \mathrm{~s}$ (40 cycles). We checked amplification products using a $2 \%$ agarose gel stained with ethidium bromide. We obtained double-strand sequences with an automated sequencer (Plateforme de séquençage et génotypage OUEST-genopole ${ }^{\circledR}$ ). New $28 \mathrm{~S}$ and COI sequences were submitted to GenBank (Table 4).

We retrieved comparative sequences of related taxa from the superfamily Brachylaimoidea from GenBank databases, as well as sequences of Clinostomum species from the superfamily Schistosomatoidea, used as the outgroup. We discarded sequences that were too short or aligned too ambiguously with our dataset. Nuclear $28 \mathrm{~S}$ sequences generated in this study were aligned using the built-in assembly algorithm implemented in CODONCODE ALIGNER software v8.0.1 (CodonCode Corporation, Dedham, MA, USA), whereas mitochondrial $\mathrm{COI}$ sequences were aligned using the on-line algorithm for coding sequences MACSE (Multiple Alignment of Coding Sequences, accounting for frameshifts and stop codons) [50].

We estimated phylogenetic relationships between our samples and sequences retrieved from GenBank by Bayesian inference (BI). We selected the best model of nucleotide substitutions prior to BI analyses using the Akaike information criterion (AIC). We used MRAIC software, v1.4.2 [42] to evaluate 24 different models of nucleotide substitutions. The resulting best models were GTR $+\mathrm{G}$ for $28 \mathrm{~S}$ rDNA and HKY $+\mathrm{G}$ for COI mtDNA (GTR: generalized time reversible; HKY: Hasegawa-Kishino-Yano). We incorporated these models in MRBAYES v3.1.1-p1 [52] for BI analyses. We conducted phylogenetic inference independently for each target gene, but also for both genes simultaneously, concatenated into a super-gene alignment of $2102 \mathrm{bp}$, although only for species and samples for which COI and 28S sequences were available. 
Table 3. Occurrence of Brachylaima sporocysts (SP) and metacercariae (MC) in C. aspersum from Arçais and Thorigné-Fouillard.

\begin{tabular}{|c|c|c|c|c|c|c|c|}
\hline & Shell size & $\mathrm{P} \% \mathrm{SP}$ & A SP & I SP & $\mathrm{P} \% \mathrm{MC}$ & A MC & $\mathrm{I} \mathrm{MC}$ \\
\hline \multicolumn{8}{|l|}{ Arçais } \\
\hline Subadults (139) & $23.93 \pm 0.36$ & $5.8(2.9-10.9)$ & $3.50 \pm 2.89$ & $69.43 \pm 35.93$ & 72.7 (64.7-79.4) & $9.21 \pm 2.12$ & $12.67 \pm 2.65$ \\
\hline Adults (138) & $30.53 \pm 0.30$ & $3.6(1.6-8.2)$ & $1.57 \pm 1.78$ & $51.40 \pm 55.49$ & $68.8(60.7-76.0)$ & $6.05 \pm 1.61$ & $8.79 \pm 2.15$ \\
\hline All snails (277) & $27.24 \pm 0.46$ & $4.7(2.8-7.9)$ & $2.68 \pm 1.79$ & $61.92 \pm 26.79$ & $70.8(65.2-75.8)$ & $7.64 \pm 1.34$ & $10.79 \pm 1.71$ \\
\hline \multicolumn{8}{|l|}{ Thorigné-Fouillard } \\
\hline Subadults (36) & $19.54 \pm 0.95$ & - & - & - & $2.8(0.5-14.2)$ & $0.72 \pm 1.47$ & 26 \\
\hline Adults (13) & $29.25 \pm 1.21$ & - & - & - & $38.5(17.7-64.5)$ & $14.92 \pm 21.31$ & $38.80 \pm 59.05$ \\
\hline All snails (49) & $22.12 \pm 1.47$ & - & - & - & $12.2(5.7-24.2)$ & $4.49 \pm 5.55$ & $36.67 \pm 46.18$ \\
\hline
\end{tabular}

P\%: prevalence, A: abundance, I: intensity. All values are means with 95\% CI in parentheses.

Table 4. Taxonomy and GenBank accession number of the $28 \mathrm{~S}$ and COI sequences for the species related to our study samples and used in subsequent phylogenetic analyses.

\begin{tabular}{|c|c|c|c|c|c|}
\hline Taxon & Stage & Host species & Country & $28 \mathrm{~S}$ & COI \\
\hline \multicolumn{6}{|l|}{ Brachylaimoidea } \\
\hline \multicolumn{6}{|l|}{ Brachylaimidae } \\
\hline \multirow{3}{*}{ Brachylaima asakawai } & A & Myodes rufocanus & Japan & LC349000 & LC349006 \\
\hline & M & Discus pauper & Japan & LC349001 & LC349007 \\
\hline & M & Succinea lauta & Japan & - & LC349008 \\
\hline \multirow[t]{3}{*}{ Brachylaima ezohelicis } & M & Ezohelix gainesi & Japan & LC198310 & LC198314 \\
\hline & M & Idem & Japan & - & LC198315 \\
\hline & M & Idem & Japan & - & LC198316 \\
\hline \multirow[t]{3}{*}{ Brachylaima mesostoma } & $\mathrm{A}$ & Turdus philomelos & Czech R & - & KP903684 \\
\hline & A & Sylvia atricapilla & Poland & - & KT074962 \\
\hline & A & Idem & Poland & - & КT074963 \\
\hline Brachylaima sp Australia & A & Mus musculus & Australia & AY222167 & - \\
\hline Brachylaima thompsoni & A & Blarina brevicauda & USA & AF184262 & - \\
\hline Brachylaima virginianum & A & Didelphis virginiana & USA & DQ060330 & - \\
\hline Postharmostomum commutatum & A & Gallus gallus & Brazil & МH915390 & MH919409 \\
\hline Zeylanurotrema speraei & A & Rhinella marina & Australia & AY222170 & - \\
\hline \multicolumn{6}{|l|}{ Leucochloridiidae } \\
\hline \multirow[t]{3}{*}{ Leucochloridium paradoxum } & $\mathrm{S}$ & Succinea sp. & Russia & KP938187 & MK882502 \\
\hline & A & $\begin{array}{c}\text { Parus major } \\
\text { Cyanistes caeruleus }\end{array}$ & Baltic coast & - & MK882503 \\
\hline & A & Idem & Baltic coast & - & MK882504 \\
\hline \multirow[t]{3}{*}{ Leucochloridium perturbatum } & A & Turdus philomelos & Czech R & KP938186 & KP903644 \\
\hline & A & Turdus merula & Czech R & AY222169 & - \\
\hline & $\mathrm{S}$ & Terrestrial snail & Poland & AF184261 & - \\
\hline \multirow[t]{3}{*}{ Leucochloridium vogtianum } & A & Acrocephalus arundinaceus & Czech R & - & KP903667 \\
\hline & A & Locustella fluviatilis & Czech R & - & KP903656 \\
\hline & A & Acrocephalus arundinaceus & Czech R & - & KP903654 \\
\hline \multirow[t]{4}{*}{ Urogonimus macrostomus } & A & Parus major & Baltic coast & AY222168 & MK882506 \\
\hline & & Cyanistes caeruleus & & & \\
\hline & A & Idem & Baltic coast & - & MK882508 \\
\hline & A & Emberiza rustica & Japan & AB494468 & MK882507 \\
\hline \multicolumn{6}{|l|}{ Schistosomatoidea } \\
\hline \multicolumn{6}{|l|}{ Clinostomidae } \\
\hline Clinostomum complanatum* & A & Phalacrocorax carbo & Japan & MH491531 & - \\
\hline Clinostomum cutaneum* & A & Ardea cinerea & Kenya & GQ339114 & KP110516 \\
\hline Clinostomum phalacrocoracis* & A & Idem & Kenya & FJ609423 & - \\
\hline \multicolumn{6}{|l|}{ Sequences in this study } \\
\hline AR-Sporo-1 & $\mathrm{S}$ & Cornu aspersum & Arçais & MN817937 & MN848408 \\
\hline AR-Sporo-2 & $\mathrm{S}$ & Idem & Arçais & MN817938 & MN848409 \\
\hline AR-Sporo-3 & $\mathrm{S}$ & Idem & Arçais & MN817939 & MN848410 \\
\hline AR-Sporo-4 & $\mathrm{S}$ & Idem & Arçais & MN817940 & MN848411 \\
\hline TF-Meta-1 & $\mathrm{M}$ & Idem & Thorigné-F. & - & MN849923 \\
\hline
\end{tabular}

Parasitic stage (A: adult, M: metacercaria, S: sporocyst), host species and country are indicated. Sequences in bold are those used for the twogene BI analysis.

Outgroup. 


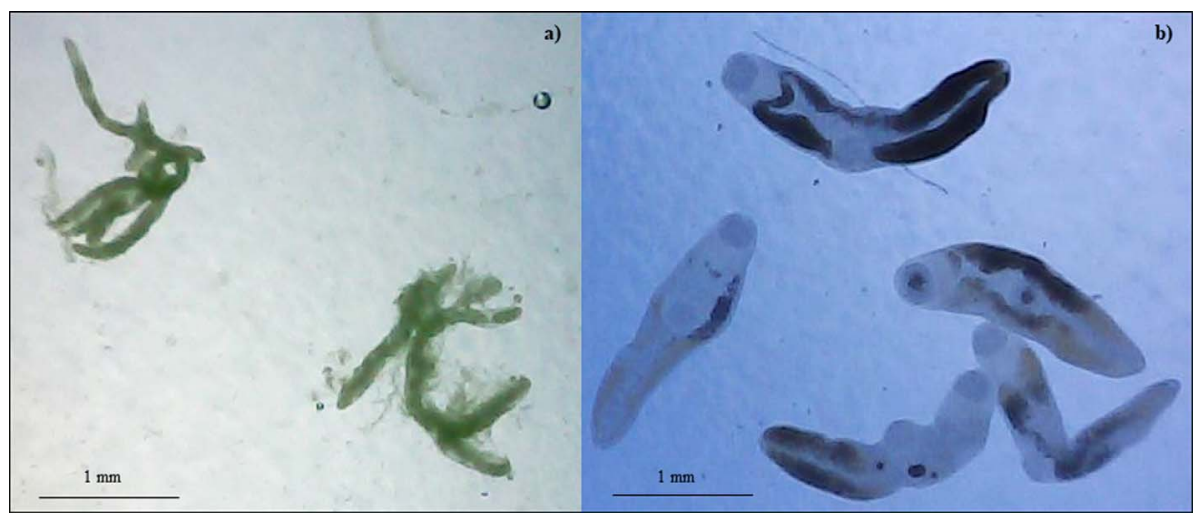

Figure 1. (a) Sporocysts and (b) metacercariae of Brachylaima found in Cornu aspersum at sites in France. Sporocysts were only recorded in Arçais, whereas metacercariae occurred in Arçais and Thorigné-Fouillard.

We approximated the posterior probabilities of trees and parameters with Markov Chain Monte Carlo (MCMC) and Metropolis coupling. We ran two independent MCMC analyses with four chains each and a temperature set to 0.2. Each chain was run for $10,000,000$ cycles with trees sampled every 100 generations. Posterior probabilities were obtained from the $50 \%$ majority rules consensus of trees sampled after discarding the trees saved before chains reached apparent stationarity (i.e., a "burn-in period" of 8000 generations). For each analysis, the average standard deviation of split frequencies after $10,000,000$ generations was well below 0.01 , indicating very good convergence between the two runs.

\section{Statistical analysis}

We performed the analyses using R, version 3.5.1 [48]. We used Bernoulli generalized linear models (GLMs) to analyze the prevalence of metacercariae and sporocysts (binary variables: infected/uninfected). We tested whether infection probability depended on site, life stage, and their interaction. We undertook the same analysis on metacercariae counts, using this time a quasi-Poisson GLM (due to evidence of overdispersion). When a variable had a significant effect, post-hoc comparisons among groups were performed using estimated marginal means and contrasts [27]. Due to the low number of positive cases, data for sporocyst counts were not analyzed statistically but simply presented (Table 3 ).

Differences were considered statistically significant at $p \leq 0.05$. We reported mean values followed by the $95 \%$ confidence interval (CI). For prevalence, we calculated CI using the score method [40].

\section{Results}

\section{Occurrence of Brachylaima spp. in Cornu aspersum from Arçais and Thorigné-Fouillard}

Land snails from both sites were infected by Brachylaima spp. with a total prevalence of $73.3 \%$ (CI [67.8\%-78.2\%]) and $12.2 \%$ (CI [5.7\%-24.2\%]) in Arçais and ThorignéFouillard, respectively (Table 3, Fig. 1). No other digenean trematodes besides Brachylaima spp. were present. In Arçais,
C. aspersum mainly plays the role of second intermediate host for Brachylaima spp. (196 among 277 snails) and harbors up to 100 metacercariae in the kidney (Table 3). More rarely, C. aspersum acts as first intermediate host (13 among 277 snails), harboring up to 100 sporocysts in the digestive gland (Table 3). In total, six snails were concomitantly infected by sporocysts and metacercariae. In Thorigné-Fouillard, no individuals of $C$. aspersum were infected by sporocysts (prevalence of $0.0 \%$, CI [0.0-7.3\%]). Cornu aspersum was found to play only the role of second intermediate host for Brachylaima spp. (5 among 49 snails) and harbored up to 100 metacercariae in the kidney (Table 3). One adult snail from ThorignéFouillard harbored metacercariae both in the kidney (63) and in the lung cavity (45).

\section{Molecular analysis and morphometrics of Brachylaima spp. in Cornu aspersum}

We obtained good quality $28 \mathrm{~S}$ rDNA and COI mtDNA sequences for four sporocysts from Arçais, and only one COI mtDNA sequence for a metacercaria from Thorigné-Fouillard. Unfortunately, DNA isolation was unsuccessful for the other samples of Brachylaima spp. sporocysts and metacercariae used for molecular analysis. The successful sequences were implemented in the phylogenetic analyses (Table 4; sequence identity matrices are presented in Supplementary Tables 1-3). Phylogenetic trees illustrating the relationships between our samples and related species from GenBank were globally well supported, with posterior probability values never below 0.5 (Fig. 2). The monophyly of the genus Brachylaima was very well supported (probability posterior value $\geq 0.67$ ), and our larval trematodes were unambiguously identified as Brachylaima species (Fig. 2).

Three samples from Arçais (AR-Sporo-2, AR-Sporo-3, and AR-Sporo-4) form a clade that could be Brachylaima mesostoma according to the COI tree (Fig. 2B). Unfortunately, 28S rDNA sequences available in GenBank for B. mesostoma were too short and could not be included in the analyses.

The other Arçais sporocyst sample (AR-Sporo-1) did not branch with the three others inside the Brachylaima clade, but with the metacercarial Thorigné-Fouillard sample (TF-Meta-1) based on the COI tree (Fig. 2B) and concatenated 
A.

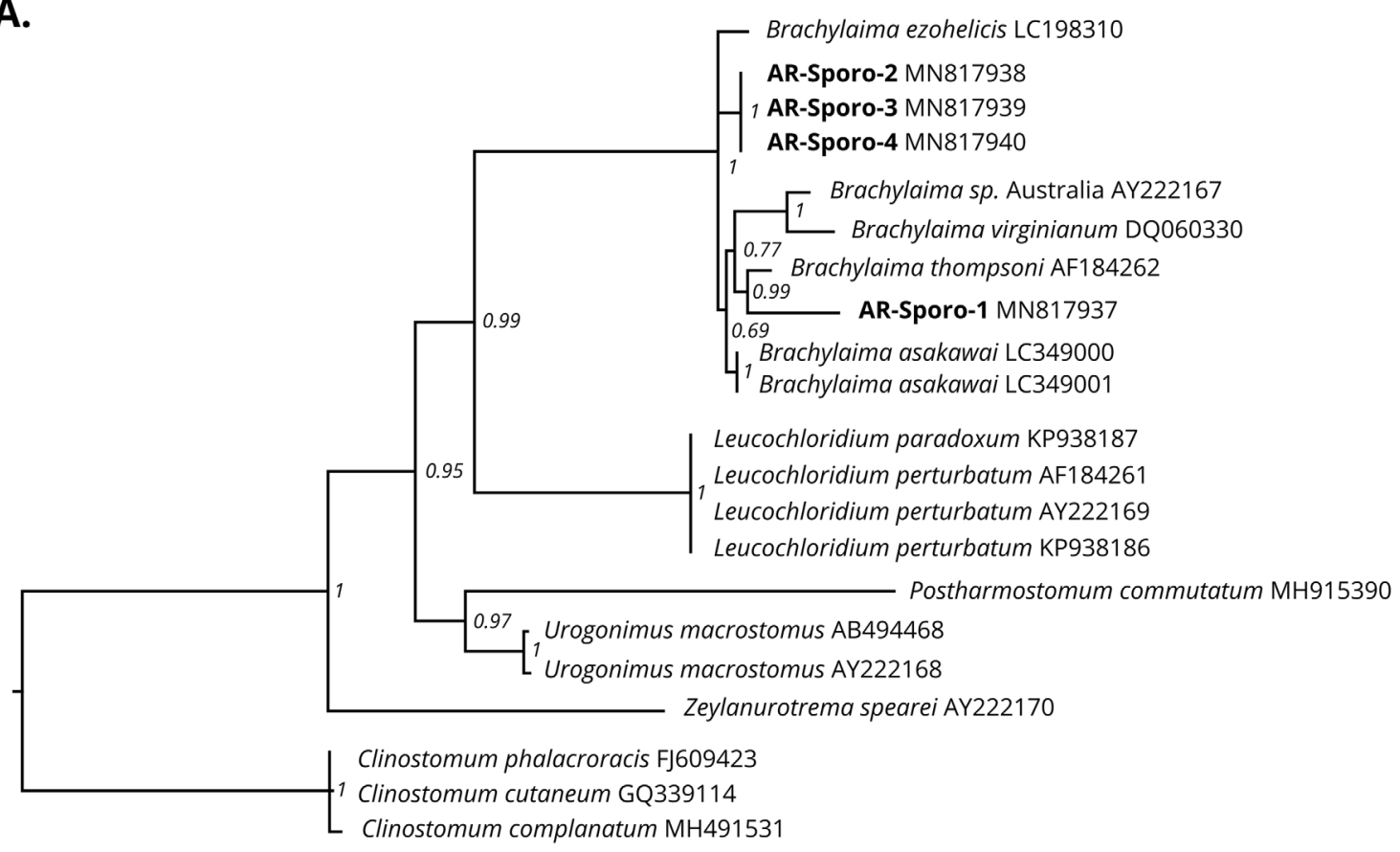

B.

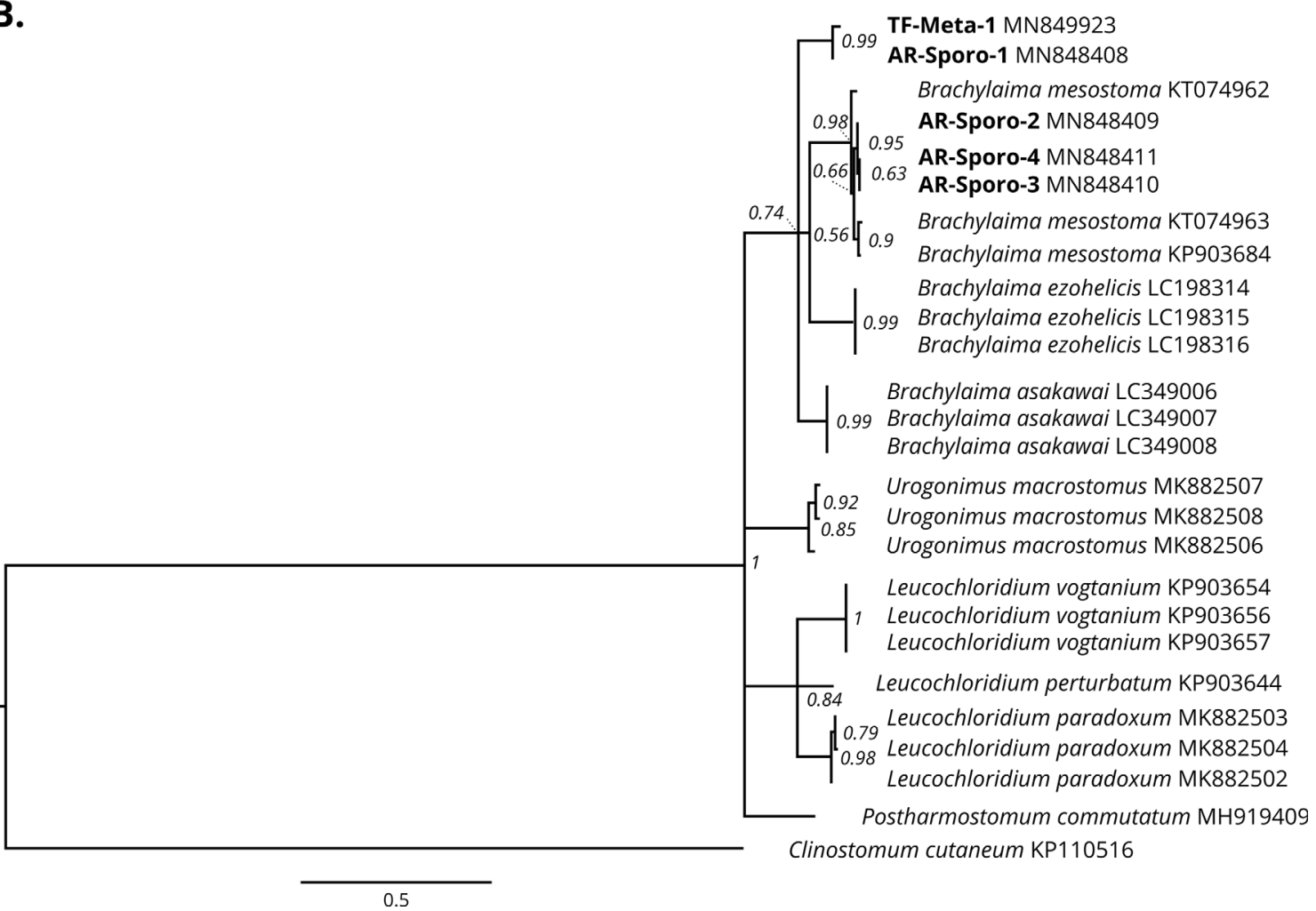

Figure 2. Fifty percent majority-rule consensus phylogram from the Bayesian inference (BI) analysis of (A) 28S rDNA, (B) mtDNA COI, and (C) both concatenated sequences of unidentified trematode specimens from two Cornu aspersum populations (in bold) and related species from the Brachylaimidae and Leucochloridiidae families. The trees are rooted using Clinostomum sp. (Family Clinostomidae) as the outgroup. Posterior probability values (in italics) are indicated near the branch nodes. Scale bars indicate the number of substitutions per nucleotide site. See Table 4 for information on taxonomy and sample origin, and Supplementary Tables 1-3 for information on the percentage of identity among sequences. 
C.

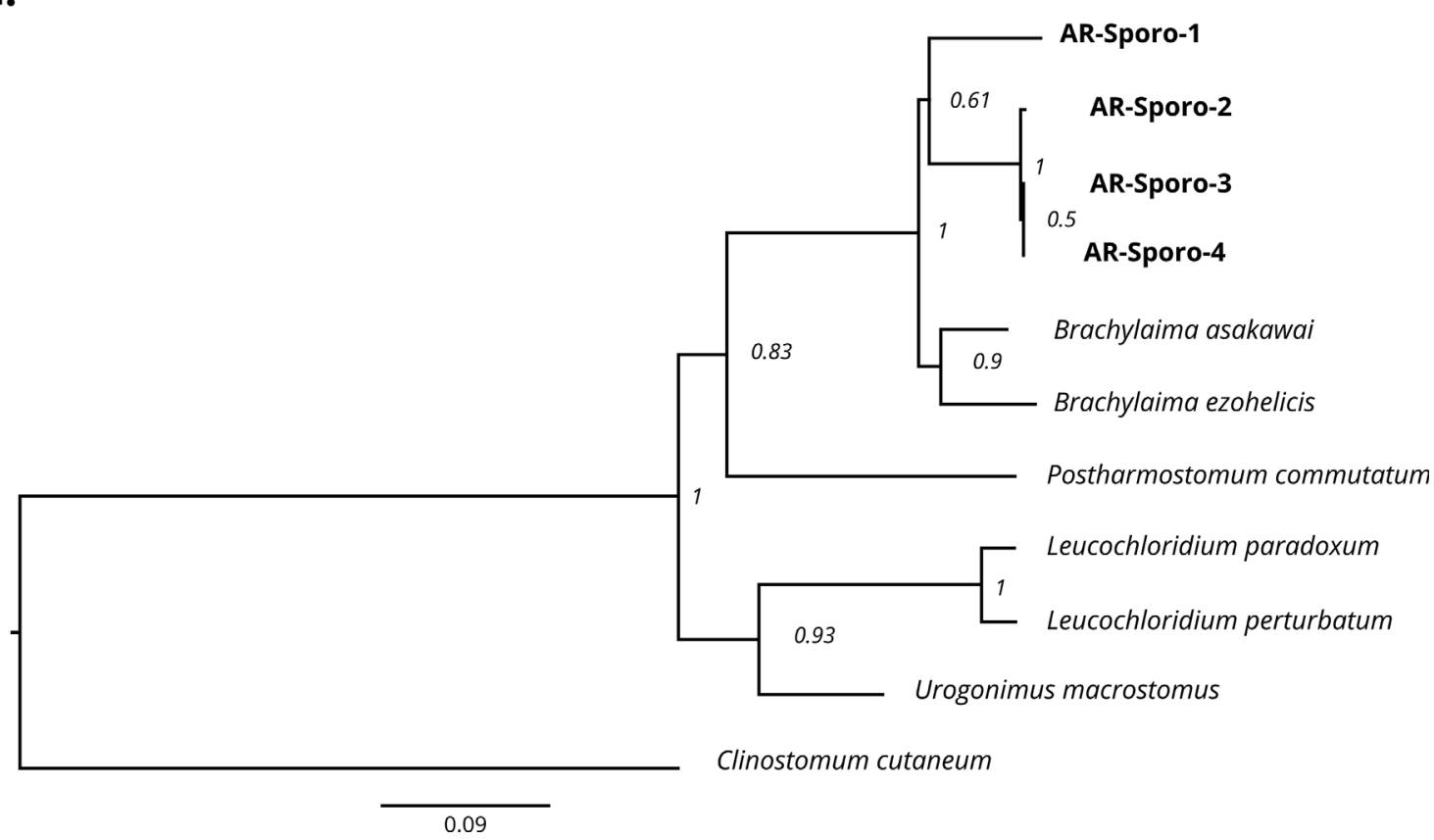

Figure 2. Continued.

Table 5. Measurements (in $\mu \mathrm{m})$ of Brachylaima metacercariae in Cornu aspersum from Thorigné-Fouillard $(N=10)$ and Arçais $(N=10)$, and comparison with the four Brachylaima species recorded in C. aspersum (B. aspersae, B. cribbi, B. llobregatensis, and B. mascomai) and with Brachylaima mesostoma. Measurements of B. aspersae and B. cribbi are reported from metacercariae found in $C$. aspersum [3, 53], those of B. llobregatensis and B. mascomai from the helicid Otala punctata [18, 42], and those of B. mesostoma from the hygromiid Helicopsis retowskii [57].

\begin{tabular}{|c|c|c|c|c|c|c|c|c|c|c|c|c|c|c|}
\hline & \multicolumn{8}{|c|}{ In $C$. aspersum } & \multicolumn{4}{|c|}{ In $O$. punctata } & \multirow{2}{*}{\multicolumn{2}{|c|}{$\frac{\text { In } H . \text { retowskii }}{\text { B. mesostoma }}$}} \\
\hline & \multicolumn{2}{|c|}{ Thorigné $(N=3)$} & \multicolumn{2}{|c|}{ Arçais $(N=4)$} & \multicolumn{2}{|c|}{ B. aspersae } & \multicolumn{2}{|c|}{ B. cribbi } & \multicolumn{2}{|c|}{ B. llobregatensis } & \multicolumn{2}{|c|}{ B. mascomai } & & \\
\hline & Mean & Range & Mean & Range & Mean & Range & Mean & Range & Mean & Range & Mean & Range & Mean & Range \\
\hline \multicolumn{15}{|l|}{ Body } \\
\hline Length & 2046 & $2000-2126$ & 2005 & $1832-2179$ & 644 & $495-882$ & 1152 & $625-1912$ & 1243 & $982-1485$ & 1321 & $604-1814$ & 1323 & $896-1566$ \\
\hline Width & 498 & & 584 & $558-611$ & 385 & $113-$ & 410 & & 407 & $822-1485$ & 419 & & 512 & $400-648$ \\
\hline \multicolumn{15}{|c|}{ Oral sucker } \\
\hline Length & 225 & & 289 & $274-316$ & 156 & & 174 & & 195 & $105-299$ & 196 & & 226 & $190-259$ \\
\hline Width & 263 & & 268 & $253-284$ & 150 & $125-173$ & 163 & $108-203$ & 179 & $137-235$ & 182 & $100-235$ & 223 & $175-265$ \\
\hline \multicolumn{15}{|c|}{ Ventral sucker } \\
\hline Length & 263 & & 237 & $221-2$ & 140 & & 137 & & 169 & $145-$ & 173 & & 174 & $8-212$ \\
\hline Width & 249 & $221-263$ & 234 & $221-253$ & 126 & $103-158$ & 153 & $103-198$ & 159 & $131-224$ & 162 & $101-224$ & 190 & $162-217$ \\
\hline \multicolumn{15}{|l|}{ Pharynx } \\
\hline Length & 144 & & 134 & $105-158$ & 96 & & 81 & & 87 & $66-132$ & 88 & $66-132$ & 123 & $101-132$ \\
\hline Width & 172 & $147-189$ & 129 & $126-137$ & 100 & $30-190$ & 97 & $60-140$ & 120 & $92-158$ & 121 & $92-158$ & 122 & $111-132$ \\
\hline
\end{tabular}

genes tree (Fig. 2C). This suggests that at least two Brachylaima species occur in Arçais, potentially corresponding to B. mesostoma and an unidentified species also occurring in Thorigné-Fouillard.

The morphometrics of Brachylaima metacercariae were similar in Arçais and Thorigné-Fouillard, but were of greater size than those of $B$. mesostoma coming from the hygromiid Helicopsis retowskii (Table 5). Metacercariae from both sites were also of greater size than those of B. aspersae, B. cribbi, B. llobregatensis, and B. mascomai known to use C. aspersum as second intermediate host (Table 5). No DNA sequences are available in GenBank for these four species infecting C. aspersum.

\section{Comparison of Brachylaima spp. in Cornu aspersum between sites and life stages}

The metacercarial prevalence in Arçais was six times higher than in Thorigné-Fouillard (analysis of deviance, $\chi_{1}^{2}=59.73$, $p<0.0001$ ), with a significant stage-by-site interaction 
$\left(\chi_{1}^{2}=10.42, p=0.001\right)$, whereas the intensity of metacercariae was more than three times lower (Table 3). The metacercarial abundance depended on both site and life stage (interaction effect, $\left.\chi_{1}^{2}=22.45, p<0.0001\right)$.

In Arçais, no significant differences between subadults and adults were detected in the prevalence and the abundance of metacercariae (contrast of marginal means: $p=0.90$ and $p=0.15$, respectively). In Thorigné-Fouillard, both prevalence (contrast $p=0.04)$ and abundance of metacercariae $(p=0.007)$ were higher in adults than in subadults (Table 3).

There was no detectable effect of site or life stage on sporocyst prevalence (all $p>0.06$ ).

\section{Discussion}

Species of the digenean trematode Brachylaima were recorded for the first time in populations of $C$. aspersum sampled in France. Two other land snail species, the helicids Cepaea nemoralis and Cepaea hortensis, were previously found to harbor Brachylaima metacercariae at another site in France (i.e., Richelieu located at $110 \mathrm{~km}$ from Arçais and $190 \mathrm{~km}$ from Thorigné-Fouillard as the crow flies), but without description of the parasite species [11]. In Poland, a recent study described the occurrence of Brachylaima mesostoma cercariae and metacercariae in three among 11 populations of C. nemoralis and $C$. hortensis, with spring prevalence up to $54 \%$ and $60 \%$, respectively [60]. In our study, C. aspersum was found to act as both first and second intermediate host in Arçais, whereas only as second in Thorigné-Fouillard. The absence of $C$. aspersum infected by sporocysts in ThorignéFouillard may be due to the low sampling effort. In fact, prevalence of Brachylaima sporocysts was low in Arçais $(\leq 5 \%)$, as generally recorded in $C$. aspersum from Spain for B. aspersae [53] and B. llobregatensis [16], and from Turkey for an undetermined Brachylaima species [26].

The prevalence of Brachylaima metacercariae in ThorignéFouillard (12\%) was about six times lower than in Arçais (71\%). This may be partly explained by differences in the sampling date, respectively mid-February (end of winter when snails were just coming out of hibernation) for Thorigné-Fouillard vs. 1 April (beginning of spring with fully active snails) for Arçais. Seasonal fluctuations occur in the metacercarial prevalence of Brachylaima spp. in Spain, with the lowest value recorded in winter $(23 \%)$ [17].

Another explanation of higher metacercarial prevalence in Arçais may be the higher density of $C$. aspersum and other land snail species potentially acting as second intermediate host (i.e., C. nemoralis and the hygromiids Cernuella virgata, Cochlicella acuta, Theba pisana, and Trochoidea elegans) than in Thorigné-Fouillard (A. Ansart, pers. obs.). This higher density favors contact between snails, and consequently, Brachylaima spp. transmission from first to second intermediate hosts [15]. Importantly, cercariae of Brachylaima emerging from sporocyst-infected snails crawl actively on humid substrate until they come into contact with a susceptible second intermediate snail host [17]. A wide specificity of Brachylaima spp. generally occurs for the second intermediate host as for B. cribbi metacercariae infecting various helicid and hygromiid species in Australia [5]. Contrastingly, the specificity of Brachylaima spp. is clearly more restricted for the first intermediate host, and even, is oioxenic for $B$. aspersae and B. llobregatensis parasitizing $C$. aspersum [16, 53]. According to the life cycle of $B$. aspersae [53], after egg ingestion by C. aspersum, the miracidium hatches and develops into a highly branched sporocyst in the digestive gland. Cercariae produced by sporocysts emerge from the first intermediate host and enter the kidney of the second via the ureter. Then, they feed on the renal epithelium to develop into nonencysted fully mature metacercariae. Cercariae are unable to infect the snail from which they are emerging; therefore, autoinfection is not possible [53]. Despite this, $C$. aspersum can be infected simultaneously with sporocysts and metacercariae of B. aspersae [53].

Differences in populations of definitive hosts between sites may induce some differences in prevalence of Brachylaima spp. in first and second intermediate hosts. Rodents are the main definitive hosts of Brachylaima spp. recorded in C. aspersum from Europe, i.e. B. aspersae, B. llobregatensis, and B. mascomai [16, 18, 53]. Populations of rodents are likely different between suburban (Thorigné-Fouillard) and rural (Arçais) sites [28], with consequences on the probability of ingesting Brachylaima spp. eggs released in rodent feces by C. aspersum used as first intermediate hosts, potentially inducing inter-site differences in parasite prevalence. Birds are also important definitive hosts of Brachylaima spp. as demonstrated for B. cribbi commonly infecting introduced European turdids (T. merula and S. vulgaris) in Australia [3, 4], as well as for B. mesostoma, Brachylaima arcuatus, and Brachylaima fuscata infecting passerines (Sylvia atricapilla, Turdus philomelos, T. merula, Garrulus glandarius) in Central Europe (Poland, Czech Republic) [24]. As for rodents, passerine diversity and abundance probably differ between rural and suburban settings [56], potentially influencing Brachylaima spp. prevalences.

The three time-higher intensity of metacercariae in C. aspersum from Thorigné-Fouillard compared to Arçais may reveal a different strategy of Brachylaima spp. depending on the site, with a higher degree of parasite aggregation in the snail population of Thorigné-Fouillard (lower prevalence with higher intensity). In Arçais, the distribution of sporocysts was strongly aggregated in the $C$. aspersum population with low prevalence (4\%) and high mean parasite intensity, about six times higher than for metacercariae present in more than $70 \%$ of the snails. Asexual reproduction of sporocysts in their snail host partly explains differences in aggregation degree between sporocysts and metacercariae [45]. Aggregation of parasitic helminths such as trematodes within host populations (i.e., small proportion of hosts infected with many parasites) is a general law of parasite ecology $[45,54]$. The aggregation degree mainly depends on the distribution of hosts and/or infective parasites across space and time, and may be influenced by parasite accumulation with host age [45, 54]. Massive infections with sporocysts or metacercariae of Brachylaima can induce extensive pathological effects, i.e. sporocysts can almost totally invade and replace the digestive gland and they can also infiltrate the pulmonary, renal, and gonadal tissues, whereas metacercariae directly feed on the renal epithelium [53]. Thus, one can expect acute harmful effects of Brachylaima spp. on 
the few snails parasitized by sporocysts in Arçais and those parasitized by metacercariae in Thorigné-Fouillard. In contrast, the lower number of Brachylaima metacercariae in subadult and adult snails from Arçais may suggest a more efficient immune response against this parasitic larval stage, potentially limiting parasite-induced lethal risk.

Concerning identification of the Brachylaima spp. in this study, our preliminary genetic data suggest that at least two different Brachylaima species parasitize $C$. aspersum at the two study sites. One of the species, using $C$. aspersum as a first intermediate host in Arçais, is very similar to B. mesostoma found in S. atricapilla (European blackcap) from Poland and T. philomelos (song thrush) from the Czech Republic [24]. The life cycle of $B$. mesostoma was previously described in the Ukraine; there, it does not involve $C$. aspersum but the hygromiid Xeropicta krynickii as a first intermediate host and various terrestrial snails (Xeropicta krynickii, Helicopsis retowskii, Helicopsis filimargo, Eobania vermiculata, Brephulopsis cylindrica, Brephulopsis bidens, Thoanteus gibber) as second hosts [57]. Recently, B. mesostoma was identified in $C$. nemoralis and $C$. hortensis from Poland used both as first and second intermediate hosts [60]. Concerning the second Brachylaima species, which is undetermined, both molecular results and similarities in metacercariae morphometrics imply that it may occur at both sites, using C. aspersum as first and second intermediate host. Moreover, the great size of metacercariae in Arçais and Thorigné-Fouillard suggests that the Brachylaima species here may be different from the four others known to use $C$. aspersum, at least as a second intermediate host (Tables 2 and 5). This hypothesis could be verified via molecular analysis, but unfortunately, no DNA sequences of these four species are available in GenBank allowing comparison with our DNA sequences. Therefore, further studies are needed to specifically identify the Brachylaima spp. recorded in populations of $C$. aspersum in France, and to assess the occurrence of B. mesostoma and other Brachylaima species. It is also important to determine what other land snail species act as intermediate hosts in the field (helicids including Cepaea spp. and hygromiids), as well as what species are definitive hosts, potentially including humans and domestic animals. Because global warming provides favorable environmental conditions for the successful spread of C. aspersum [14], and therefore the spread of parasites such as Brachylaima spp. [15], it is crucial to evaluate the potential risk to human and veterinary health.

\section{Supplementary materials}

Supplementary material is available at https://www.parasitejournal.org/10.1051/parasite/2020012/olm

Supplementary Table 1. Percentages of identity between the $28 \mathrm{~S}$ sequences used in the present study. Values were estimated based on aligned sequences using the SeqinR package (Charif and Lobry 2007, DOI: 10.1007/978-3-540-35306-5_10).

Supplementary Table 2. Percentages of identity between the COI sequences used in the present study. Values were estimated based on aligned sequences using the SeqinR package (Charif and Lobry 2007, DOI: 10.1007/978-3-540-35306-5_10).
Supplementary Table 3. Percentages of identity between the $\mathrm{COI}+28 \mathrm{~S}$ supergene alignment sequences used in the present study. GenBank accession numbers refer respectively to $28 \mathrm{~S}$ and COI sequences. Values were estimated based on aligned sequences using the SeqinR package (Charif and Lobry 2007, DOI: 10.1007/978-3-540-35306-5_10).

Acknowledgements. We gratefully acknowledge Valérie Briand (UMR ECOBIO 6553) for her bibliographical support. We also thank the ECOBIO PEM (Plateforme d'Écologie Moléculaire) for technical support in molecular analyses. The authors declare that there are no competing interests.

\section{References}

1. Ansart A, Madec L, Guiller A. 2009. Cornu aspersum. CABI invasive species compendium. URL: http://www.cabi.org/isc/ datasheet/26821.

2. Bush AO, Lafferty KD, Lotz JM, Shostak AW. 1997. Parasitology meets ecology on its own terms: Margolis revisited. Journal of Parasitology, 83, 575-583.

3. Butcher AR, Grove DI. 2001. Description of the life-cycle stages of Brachylaima cribbi n. sp. (Digenea: Brachylaimidae) derived from eggs recovered from human faeces in Australia. Systematic Parasitology, 49, 211-221.

4. Butcher AR, Grove DI. 2005. Second intermediate host land snails and definitive host animals of Brachylaima cribbi in Southern Australia. Parasite, 12, 31-37.

5. Butcher AR, Grove DI. 2005. Seasonal variation in rates of sporocyst and metacercarial infection by Brachylaima cribbi in helicid and hygromiid land snails on the Yorke Peninsula, South Australia. Australian Journal of Zoology, 53, 375-382.

6. Butcher AR, Parasuramar P, Thompson CS, Grove DI. 1998. First report of the isolation of an adult worm of the genus Brachylaima (Digenea: Brachylaimidae), from the gastrointestinal tract of a human. International Journal for Parasitology, 28, 607-610.

7. Colella V, Giannelli A, Brianti E, Nascimento Ramos RA, Cantacessi C, Dantas-Torres F, Otranto D. 2015. Feline lungworms unlock a novel mode of parasite transmission. Scientific Reports, 15, 13105.

8. Colella V, Mutafchiev Y, Cavalera MA, Giannelli A, Lia RP, Dantas-Torres F, Otranto D. 2016. Development of Crenosoma vulpis in the common garden snail Cornu aspersum: implications for epidemiological studies. Parasites \& Vectors, 9, 208.

9. Di Cesare A, Crisi PE, Bartolini R, Iorio R, Talone T, Filippi L, Traversa D. 2013. Larval development of the feline lungworm Aelurostrongylus abstrusus in Helix aspersa. Parasitology Research, 112, 3101-3108.

10. Di Cesare A, Crisi PE, Bartolini R, Iorio R, Talone T, Filippi L, Traversa D. 2015. Larval development of Angiostrongylus vasorum in the land snail Helix aspersa. Parasitology Research, $114,3649-3655$.

11. Dollfus R-P. 1961. Contribution à la faune parasitaire de la région de Richelieu. Chapitre I. Liste des parasites par hôtes. Annales de Parasitologie Humaine et Comparée, 36(3), 174-261.

12. Dunn AM, Torchin ME, Hatcher MJ, Kotanen PM, Blumenthal DM, Byers JE, Coon CAC, Frankel VM, Holt RD, Hufbauer RA, Kanarek AR, Schierenbeck KA, Wolfe LM, Perkins SE. 2012. Indirect effects of parasites in invasions. Functional Ecology, 26, 1262-1274. 
13. Evans-Gilbert T, Lindo JF, Henry S, Brown P, Christie CDC. 2014. Severe eosinophilic meningitis owing to Angiostrongylus cantonensis in young Jamaican children: case report and literature review. Paediatrics and International Child Health, 34, 148-152.

14. Gaitán-Espitia JD, Belén Arias M, Lardies MA, Nespolo RF. 2013. Variation in thermal sensitivity and thermal tolerances in an invasive species across a climatic gradient: lessons from the land snail Cornu aspersum. PLoS One, 8, e70662.

15. Gállego L, González-Moreno O, Gracenea M. 2014. Terrestrial edible land snails as vectors for geographic dissemination of Brachylaima species. Journal of Parasitology, 100, 674-678.

16. González-Moreno O, Gracenea M. 2006. Life cycle and description of a new species of Brachylaimid (Trematoda: Digenea) in Spain. Journal of Parasitology, 92, 1305-1312.

17. Gracenea M, Gállego L. 2017. Brachylaimiasis: Brachylaima spp. (Digenea: Brachylaimidae) metacercariae parasitizing the edible snail Cornu aspersum (Helicidae) in Spanish public marketplaces and health-associated risk factors. Journal of Parasitology, 103, 440-450.

18. Gracenea M, González-Moreno O. 2002. Life cycle of Brachylaima mascomai $\mathrm{n}$. sp. (Trematoda: Brachylaimidae), a parasite of rats in the Llobregat Delta (Spain). Journal of Parasitology, $88,124-133$

19. Grewal SK, Grewal PS, Tan L, Adams BJ. 2003. Parasitism of molluscs by Nematodes: types of associations and evolutionary trends. Journal of Nematology, 35, 146-156.

20. Guiller A, Madec L. 2010. Historical biogeography of the land snail Cоrnu aspersum: a new scenario inferred from haplotype distribution in the Western Mediterranean basin. BMC Evolutionary Biology, 10, 18.

21. Guiller A, Martin M-C, Hiraux C, Madec L. 2012. Tracing the invasion of the Mediterranean land snail Cornu aspersum aspersum becoming an agricultural and garden pest in areas recently introduced. PLoS One, 7, e49674.

22. Guisantes JA, Benito A, Estibalez JJ, Mas-Coma S. 1994. High parasite burdens by Brachylaima (Brachylaima) sp. (Trematoda: Brachylaimidae) in two dogs in the north of Spain. Research and Reviews in Parasitology, 54, 255-258.

23. Gürelli G, Göçmen B. 2007. Natural infection of Helix aspersa (Mollusca: Pulmonata) by Dicrocoeliidae (Digenea) larval stages in Izmir, Turkey. Türkiye Parazitoloji Dergisi, 31, $150-153$

24. Heneberg P, Sitko J, Bizos J. 2016. Molecular and comparative morphological analysis of central European parasitic flatworms of the superfamily Brachylaimoidea Allison, 1943 (Trematoda: Plagiorchiida). Parasitology, 143(4), 455-474.

25. Kerney MP, Cameron RAD, Bertrand A. 2006. Guide des escargots et limaces d'Europe. Paris: Delachaux et Niestle.

26. Köse M, Eser M, Kartal K, Bozkurt MF. 2015. Infections of larval stages of Dicrocoelium dendriticum and Brachylaima sp. in brown garden snail, Helix aspersa, in Turkey. Korean Journal of Parasitology, 53, 647-651.

27. Lenth R. 2019. Emmeans: Estimated Marginal Means, aka Least-Squares Means. R package version 1.3.3. https://CRAN. R-project.org/package=emmeans.

28. Łopucki R, Mroz I, Berliński L, Burzych M. 2013. Effects of urbanization on small-mammal communities and the population structure of synurbic species: an example of a medium-sized city. Canadian Journal of Zoology, 91, 554-561.

29. Madec L, Desbuquois C, Coutellec-Vreto MA. 2000. Phenotypic plasticity in reproductive traits: importance in the life history of Helix aspersa (Mollusca: Helicidae) in a recently colonized habitat. Biological Journal of the Linnean Society, 69, 25-39.
30. Mas-Coma S, Montoliu I, Valero MA. 1984. Méthodologie d'étude morphométrique de la variabilité intraspécifique chez les digènes de la famille Brachylaimidae Joyeux et Foley, 1930. Bulletin de la Société Neuchâteloise des Sciences Naturelles, 107, 185-195.

31. Meerburg BG, Singleton GR, Kijlstra A. 2009. Rodent-borne diseases and their risks for public health. Critical Reviews in Microbiology, 35, 221-270.

32. Ministère Français Agriculture, Agroalimentaire et Forêt. 2013. $14^{\text {ème }}$ legislature, Journal Officiel. http://www2.assembleenationale.fr/questions/detail/14/QE/20692.

33. Miura O, Kuris AM, Torchin ME, Hechinger RF, Dunham EJ, Chiba S. 2005. Molecular-genetic analyses reveal cryptic species of trematodes in the intertidal gastropod, Batillaria cumingi (Crosse). International Journal for Parasitology, 35, 793-801.

34. Mobedi I, Fakhar M, Irshadullah M, Rahimi-Esboei B, Gholami S, Fraija-Fernandez N. 2017. New record of Brachylaima sp. (Digenea: Brachylaimidae) from a stray dog in North Iran. Iranian Journal of Parasitology, 12, 606-613.

35. Morand S. 1988. Contribution à l'étude d'un système hôtesparasites : nématodes associés à quelques mollusques terrestres. Thèse de l'Université de Rennes 1. Rennes, France: University of Rennes 1. p. 335.

36. Morand S. 1989. Cycle évolutif de Angiostoma aspersae Morand, 1986 parasite de la cavité palléale de Helix aspersa Müller. Annales de Parasitologie Humaine et Comparée, 64, 340-346.

37. Morand S, Petter AJ. 1986. Nemhelix bakeri n.gen., n.sp. (Nematoda : Cosmocercinae) parasite de l'appareil génital de Helix aspersa (Gastropoda : Helicidae) en France. Canadian Journal of Zoology, 64, 2008-2011.

38. Nakao M, Waki T, Sasaki M, Anders JL, Koga D, Asakawa M. 2017. Brachylaima ezohelicis sp. nov. (Trematoda: Brachylaimidae) found from the land snail Ezohelix gainesi, with a note of an unidentified Brachylaima species in Hokkaido, Japan. Parasitology International, 66, 240-249.

39. Naya DE, Catalán T, Artacho P, Gaitán-Espitia JD, Nespolo RF. 2011. Exploring the functional association between physiological plasticity, climatic variability, and geographical latitude: lessons from land snails. Evolutionary Ecology Research, 13, $1-13$.

40. Newcombe RG. 1998. Two-sided confidence intervals for the single proportion: comparison of seven methods. Statistics in Medicine, 17, 857-872.

41. Nicolai A, Vernon P, Lenz R, Le Lannic J, Briand V, Charrier M. 2013. Well wrapped eggs: effects of egg shell structure on heat resistance and hatchling mass in the invasive land snail Cornu aspersum. Journal of Experimental Zoology, 319A, 63-73.

42. Nylander JAA. 2004. MrAIC. pl. Program distributed by the authorUppsala: Evolutionary Biology Centre, Uppsala University. https://github.com/nylander.

43. Pavlov P. 1946. Infestation expérimentale d'animaux domestiques par Brachylaemus. Annales de Parasitologie Humaine et Comparée, 21, 94-95.

44. Petter AJ. 1974. Le cycle évolutif de Morerastrongylus andersoni (Petter, 1972). Annales de Parasitologie Humaine et Comparée, 49(1), 69-82.

45. Poulin R. 1998. Evolutionary ecology of parasites - from individuals to communities. London: Chapman \& Hall.

46. Poulin R, Paterson RA, Townsend CR, Tompkins DM, Kelly DW. 2011. Biological invasions and the dynamics of endemic diseases in freshwater ecosystems. Freshwater Biology, 56, 676-688. 
47. Prenter J, MacNeil C, Dick JTA, Dunn AM. 2004. Roles of parasites in animal invasions. Trends in Ecology and Evolution, $19,385-390$

48. R Core Team. 2018. R: a language and environment for statistical computing (version 3.5.1). Vienna, Austria: R Foundation for Statistical Computing. Retrieved from http://www.R-project.org/.

49. Rae R. 2017. The gastropod shell has been coopted to kill parasitic nematodes. Scientific Reports, 7, 4745.

50. Ranwez V, Harispe S, Delsuc F, Douzery EJ. 2011. MACSE: Multiple Alignment of Coding SEquences accounting for frameshifts and stop codons. PloS One, 6, e22594.

51. Rojo-Vazquez FA, Cordero Del Campillo M. 1974. Le cycle biologique de Neostrongylus linearis. Annales de Parasitologie Humaine et Comparée, 49, 685-699.

52. Ronquist F, Huelsenbeck JP. 2003. MrBayes 3: Bayesian phylogenetic inference under mixed models. Bioinformatics, 19 , $1572-1574$.

53. Segade P, Crespo C, García N, García-Estévez JM, Arias C, Iglesias R. 2011. Brachylaima aspersae n. sp. (Digenea: Brachylaimidae) infecting farmed snails in NW Spain: morphology, life cycle, pathology, and implications for heliciculture. Veterinary Parasitology, 175, 273-286.

54. Shaw DJ, Dobson AP. 1995. Patterns of macroparasite abundance and aggregation in wildlife populations: a quantitative review. Parasitology, 111, 111-133.
55. Spratt DM. 2005. Australian ecosystems, capricious food chains and parasitic consequences for people. International Journal for Parasitology, 35, 717-724.

56. Sprau P, Mouchet A, Dingemanse NJ. 2017. Multidimensional environmental predictors of variation in avian forest and city life histories. Behavioral Ecology, 28(1), 59-68.

57. Stenko EN, Stenko RP. 1988. Żyzniennyj cykl trematody, Brachylaima mesostoma. Vestnik Zoologii, 1, 57-62. [in Ukrainian].

58. Tkach VV, Kudlai O, Kostadinova A. 2016. Molecular phylogeny and systematics of the Echinostomatoidea Looss, 1899 (Platyhelminthes: Digenea). International Journal for Parasitology, 46, 171-185.

59. Waki T, Sasaki M, Mashino K, Iwaki T, Nakao M. 2017. Brachylaima lignieuhadrae n. sp. (Trematoda: Brachylaimidae) from land snails of the genus Euhadra in Japan. Parasitology International, 74, 101992.

60. Zbikowska E, Marszewska A, Cichy A, Templin J, Smorag A, Strzała T. 2020. Cepaea spp. as a source of Brachylaima mesostoma (Digenea: Brachylaimidae) and Brachylecithum sp. (Digenea: Dicrocoeliidae) larvae in Poland. Parasitology Research, 119, 145-152.

Cite this article as: Gérard C, Ansart A, Decanter N, Martin M-C \& Dahirel M. 2020. Brachylaima spp. (Trematoda) parasitizing Cornu aspersum (Gastropoda) in France with potential risk of human consumption. Parasite 27, 15.

- PARASTE

An international open-access, peer-reviewed, online journal publishing high quality papers on all aspects of human and animal parasitology

Reviews, articles and short notes may be submitted. Fields include, but are not limited to: general, medical and veterinary parasitology; morphology, including ultrastructure; parasite systematics, including entomology, acarology, helminthology and protistology, and molecular analyses; molecular biology and biochemistry; immunology of parasitic diseases; host-parasite relationships; ecology and life history of parasites; epidemiology; therapeutics; new diagnostic tools.

All papers in Parasite are published in English. Manuscripts should have a broad interest and must not have been published or submitted elsewhere. No limit is imposed on the length of manuscripts.

Parasite (open-access) continues Parasite (print and online editions, 1994-2012) and Annales de Parasitologie Humaine et Comparée (1923-1993) and is the official journal of the Société Française de Parasitologie. http://parasite.edmgr.com/ 